\title{
Sonographic parameters of the pancreas and gall bladder in healthy men from Podillya region of Ukraine of different somatotypes
}

\author{
Igor Gunas $^{1 *}$, Sergiy Prokopenko ${ }^{2,}$ Marina Melnik $^{2}$
}

${ }^{1}$ International Academy of Integrative Anthropology, Pyrogov 56, Vinnytsia, 21018, Ukraine

${ }^{2}$ Vinnitsa National Medical University named after M.I. Pirogov, Pyrogov 56, Vinnytsia, 21018, Ukraine

\begin{tabular}{l}
\hline ARTICLE INFO \\
\hline Received 07 March 2016 \\
Accepted 01 April 2016 \\
\hline
\end{tabular}

\section{Keywords:}

pancreas, gall bladder,

ultrasound, mature age,

constitutional differences.

\begin{abstract}
In this work, we undertook a study of the sonographic parameters of the pancreas and gall bladder in healthy men with different somatotypes. The study-subjects were from the Podillya region of Ukraine. Herein, the majority of gallbladder dimensions (length, thickness, cross-sectional area and volume) in men type-classified as endo-mesomorphic, were significantly higher when compared with men in general and with those of the meso- and ecto-mesomorphic somatotype. Furthermore, the dimensions of the pancreas (width of head and tail length) in mesomorphic males were significantly higher than that of endo-mesomorphic males. The rest of the studied parameters (length, longitudinal cross section area of the gall bladder, the thickness of the head, body and head length, the width of the body and tail of the pancreas) in men of the different somatotypes have no significant differences.
\end{abstract}

\section{INTRODUCTION}

Diseases of the pancreas and gallbladder occupy a leading position in the need for abdominal surgery. Today, the widespread use of laparoscopic and minimally invasive techniques in malformations of these bodies requires clarification and detail specification that is greater than previously established criteria of the variant anatomy of these areas [1,2].

It should be noted that, sometimes, the interpretation of high-quality ultrasound images that were obtained in a methodically correct manner, can be difficult, especially when assessing the size of the pancreas and gall bladder. This comes about because of their pronounced individual variability [3]. There is also a need to take into account the differences of organ size due to age variation $[4,5,6]$. Based on the identified differences in the form and size of the pancreas and gall bladder in patients with various anthropo-somatometric indicators, a number of researchers have ascertained that the mentioned dependence affects the human constitution $[7,8]$. Therefore, when deciding whether there is an increase or decrease of the studied organs, it is of primary necessity to pay attention not to the average standards of their size, but on the features of their configuration

\footnotetext{
* Corresponding author

e-mail: igor.gunas@mail.ru:

phone: 067-1210005
}

and size characteristics that are evident in those of diverse constitutional types.

The aim of this study was to determine the features of sonographic parameters of the pancreas and gall bladder in healthy men. The study subjects (of different somatotypes) were from the Podilski region of Ukraine.

\section{MATERIALS AND METHODS}

The Piogov Scientific and Research Center (VNMU) in Ukraine conducted a comprehensive survey of 93 apparently healthy, urban third generation males of the first mature age living in the Podillya region of Ukraine, and who had no complaints at the time of the survey with regard to health and chronic disease in anamnesis.

In this work, we utilized Echo Metric indicators of the gallbladder and pancreas measured by way of the ultrasound diagnostic system, "CAPASEE" SSA-220A (Toshiba, Japan), a convex detector with a working frequency of $3.75 \mathrm{MHz}$ under conventional methods [9]. In so-doing, we defined: length, width, thickness, area longitudinal and cross sections of the gallbladder (the volume being obtained by way of employing the formula $\mathrm{V}=0,524 \times$ length $\times$ width $\times$ thickness); thickness, width and height of the head of the pancreas; width and height of the body and tail of the pancreas. 
The anthropometric examination was conducted in accordance with the scheme of V.V. Bunak (a modification of that of P.P. Shaparenko) [10]. To evaluate the somatotype, we employed the mathematical scheme of J.L. Carter, B.H. Heath [11]. Fat, bone and muscle components of body weight were evaluated according to the formulas advanced by J. Matiegka [12].

Statistical analysis of the results was conducted through utilizing the package "STATISTICA 6.1" (in the possession of the Pirogov Scientific and Research Center VNMU, license № AXXR910A374605FA) through ascertaining parametric and nonparametric methods of result assessment.

\section{RESULTS AND DISCUSSION}

The results of the study of the sonographic parameters of the pancreas and gallbladder in healthy men with different somatotypes, are given in Table 1.

When analyzing the data derived by way of ultrasound examination of the pancreas and gallbladder of individuals of different somatotypes, previous researchers found that the average value of all the studied parameters in test-subjects belonging to different somatotypes were significantly different from the average "good" values of these indices. Thus, somatotypological conditionality size of the investigated organs, is evident $[1,8]$.

Moreover, research has established that there is a relationship between the configuration of the gallbladder and its size in individuals of differing somatotypes. In persons of the asthenic type, a cylindrical shape is most commonly seen, whereas, in representatives with a hypersthenic type - the gall-bladder is pear-shaped gallbladder. Moreover, in those who are of the transitional somatic types (micromesosomic and mezomacrosomic), all type forms of gallbladder are noticeable, but there is a predominance of fusiform and cylindrical forms [1] (Fig. 1).

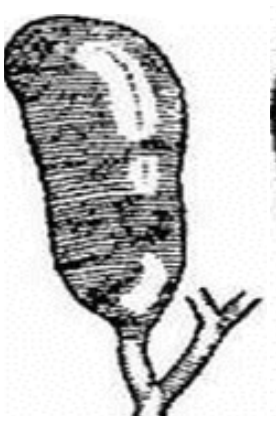

a

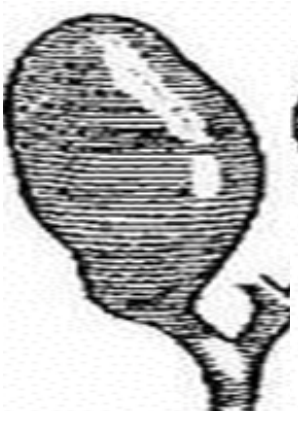

b c

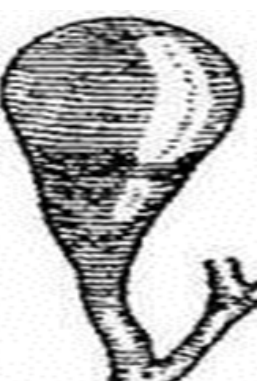

Figure 1. Variants forms of gallbladder: a) cylindrical; b) spindle; c) pear-shaped [13]

In our work, we established that in men who are endomesomorphic, the length of their gallbladder was significantly ( $p<0.05$ in both cases) higher, when compared with men who are categorized as being either meso- or ectomesomorphic. In addition, the thickness of the gallbladder in males, overall, is significantly $(\mathrm{p}<0.05)$ higher, when compared with men who are considered as being ecto-mesomorphic, and significantly lower $(\mathrm{p}<0.05)$, when compared with endo-mesomorphic individuals. This indicator in mesomorphic males is also significantly $(\mathrm{p}<0.05)$ higher, when such are compared with ecto-mesomorphic individuals. Moreover, the generated figure for endo-mesomorphic males is significantly ( $\mathrm{p}<0.01$ for both) higher when compared to that of meso- and ecto-mesomorphic individuals. As to cross-sectional area of the gallbladder and gallbladder volume, in endo-mesomorphic males, this is significantly ( $p<0,05-0,01)$ higher than that of men in general, and that of meso- and ecto-mesomorphic males.

The shape and size of the pancreas in the frontal and sagittal plane has been revealed to be of great importance. These characteristics may influence the process of allocation with regard to the organ during surgery [13]. By way of anatomical studies, there are three basic pancreatic forms with regard to shape and severity of head and tail of gland. These are: hammer-like or B-shaped (massive head with clear and thin isthmus and elongated tail), club-shaped or K-like (with massive pancreatic head and elongated tail, but not a marked sharp difference in the place of transition of the head gland in the body) and tongue-like or V-like (the head of gland being almost without contour, not massive and only slightly wider than the body, or even identical with regard to widths, shorter tail) [14] (Fig. 2). According to the data generated by M.I. Gulman et al. [1], in male asthenics, the $\mathrm{B}$-shaped (hammer-like) is most common, whereas in those who are normosthenic - it is K-like (club-shaped), and in the hypersthenic, V-shaped (tongue-like).

We also ascertained that the width of the head and length tail of the pancreas in mesomorphic males is significantly $(\mathrm{p}<0.05)$ greater and has a trend $(\mathrm{p}=0.057)$ to greater significance, when compared with endo-mesomorphic males. However, length, longitudinal cross section area of the gallbladder, the thickness of the head, body and head length, the width of the body and tail of the pancreas were seen to have no significant differences in males of different somatotypes.

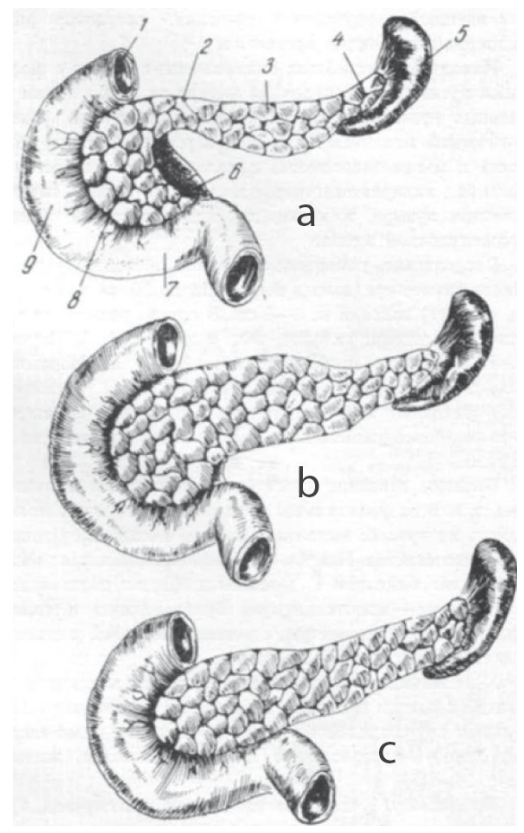

Figure 2. Variants of the pancreas forms: a) hammer-like; b) clubshaped; c) tongue-like [http://surgeryinfo.ru/podzheludochnayazheleza/] 
Table 1. Percentile scope of sonographic sizes of gallbladder (GB) and pancreas $(\mathrm{P})$ in healthy men with different somatotypes. Study subjects from the Podillya region of Ukraine

\begin{tabular}{|l|c|c|c|}
\hline \multicolumn{1}{|c|}{ Sonographic sizes } & $\begin{array}{c}\text { Mesomorph } \\
(\mathrm{n}=42)\end{array}$ & $\begin{array}{c}\text { Ecto- } \\
\text { mesomorph } \\
(\mathrm{n}=12)\end{array}$ & $\begin{array}{c}\text { Endo- } \\
\text { mesomorph } \\
(\mathrm{n}=21)\end{array}$ \\
\hline Length GB $(\mathrm{mm})$ & $66,0-76,0$ & $65,0-86,0$ & $65,0-76,5$ \\
\hline Width GB $(\mathrm{mm})$ & $21,0-27,0$ & $20,2-27,8$ & $24,0-30,0$ \\
\hline Thickness GB $(\mathrm{mm})$ & $24,5-28,5$ & $23,0-25,1$ & $26,8-32,3$ \\
\hline Area longitudinal section GB (cm2) & $10,8-14,7$ & $10,4-14,2$ & $13,2-16,1$ \\
\hline Area cross-section GB (cm2) & $4,33-6,09$ & $3,51-5,68$ & $5,29-7,61$ \\
\hline Volume GB (cm3) & $19,2-28,1$ & $16,0-26,4$ & $23,7-35,7$ \\
\hline Length of the head P (mm) & $22,5-27,0$ & $22,3-25,6$ & $23,0-26,0$ \\
\hline Width of the head P (mm) & $23,0-27,5$ & $21,1-24,0$ & $21,3-26,2$ \\
\hline Thickness of head P (mm) & $23,0-28,9$ & $20,2-27,4$ & $23,3-25,2$ \\
\hline Body length P $(\mathrm{mm})$ & $13,5-15,5$ & $12,7-15,1$ & $13,5-15,5$ \\
\hline Width of the body P (mm) & $13,5-18,0$ & $12,6-16,8$ & $15,0-17,6$ \\
\hline Length of the tail P (mm) & $19,4-24,3$ & $18,6-21,2$ & $18,4-22,1$ \\
\hline Width of the tail P $(\mathrm{mm})$ & $18,9-24,5$ & $18,4-24,9$ & $20,4-23,0$ \\
\hline
\end{tabular}

\section{CONCLUSIONS}

The majority of the gallbladder dimensions (length, thickness, cross-sectional area and volume) in endo-mesomorphic males is significantly greater, when compared with men in general and those of the meso and ecto-mesomorphic somatotypes. Moreover, the dimensions of the pancreas (width of head and length of tail) in mesomorphic men, is significantly greater when compared with endo-mesomorphic males. The rest of studied parameters (length, longitudinal cross section area of the gallbladder, the thickness of the head, body and head length, the width of the body and tail of the pancreas) in men of different somatotypes was seen to have no significant differences.

\section{REFERENCES}

1. Gulman M.I. et al. The anatomical features of the structure of hepato-pancreatic-duodenal zone. Siberian Medical Journal. 4, 1999.

2. Johnson C.D., Schmit J.D. Mayo Clinic Gastoreintestinal Imaging Review. Rochester (USA): Mayo Clinic Scientific Press. 737, 2013.

3. Guenter Schmidt, Lucas Greiner, Dieter, Nuernberg. Differential Diagnosis in Ultrasound Imaging, $2^{\text {nd }}$ edition edition. Thieme. 580, 2014.

4. Belik N.V. et al. Age, gender and somatotypological features of size and shape of the gall bladder in healthy city teenagers of Podillya. Biomedical and Biosocial Anthropology. 4, 2005.

5. Paul Allan, Grant Baxter, Michael Weston. Clinical Ultrasound, 2-Volume Set. Churchill Livingstone, 1624, 2011.

6. Mirko D'Onofrio. Ultrasonography of the Pancreas: Imaging and Pathologic Correlations. Springer Science \& Business Media, 205, 2012.

7. Chaplygina E.V. et al. The dependence of volume of the liver from somatotype and gender of the patient. Scientific Review. 7, 2013.

8. Bakhareva N.S. The morphometric parameters of the pancreas, depending on the somatotype, sex and age men affiliation. International Scientific Research Journal. 1, 2013.

9. Tchacarski Valery et al. Atlas of diagnostic ultrasound. First English Edition, Sofia, 2015.

10. Shaparenko P.P. Anthropometry. Vinnitsa, 71, 2000.

11. Carter J.E.L. The Heath-Carter anthropometric somatotype. Instruction Manual. Surrey, Canada: TeP and Rosscraft, 154, 2002.

12. Nikolic S. et al. Analysis of body mass components in national club football players in republic of Macedonia. Medicine Archives. 68, 3, 2014.

13. Tikhomirova V.D. Children Operative Surgery: A Practical Guide. M.: OOO "Izdatelstvo" Medicinskoe Informacionnoe Agenstvo 872, 2011.

14. Forbes A. et al. Atlas of Clinical Gastroenterology. 3ed. Edinburgh: Elsevier Mosby. 358, 2011. 